\title{
Next-Generation Laser for Inertial Confinement Fusion
}

C. Marshall, C. Bibeau, A. Bayramian, R. Beach, C. Ebbers, M. Emanuel, B. Freitas, S. Fulkerson, E. Honea, B. Krupke, J. Lawson, C. Orth, S. Payne, C. Petty, H. Powell, K. Schaffers, J. Skidmore, L. Smith, S. Sutton, S. Telford

This article was submitted to

Optical Society of America $13^{\text {th }}$ Topical Meeting on Advanced SolidState Lasers, Coeurd' Alene, ID 02/02/98 - 02/04/98

U.S. Department of Energy

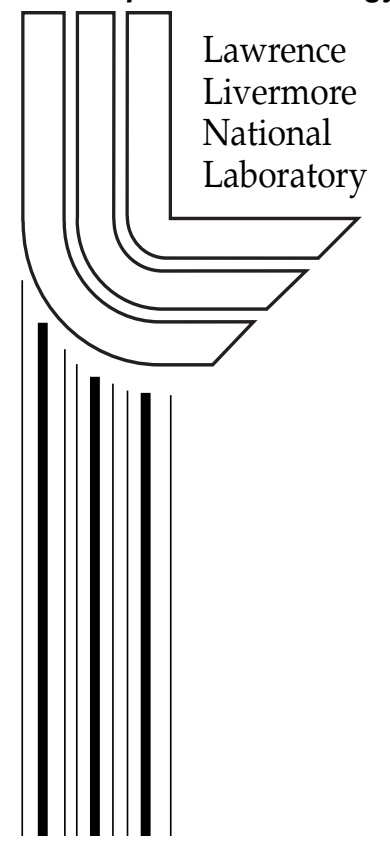




\section{DISCLAIMER}

This document was prepared as an account of work sponsored by an agency of the United States Government. Neither the United States Government nor the University of California nor any of their employees, makes any warranty, express or implied, or assumes any legal liability or responsibility for the accuracy, completeness, or usefulness of any information, apparatus, product, or process disclosed, or represents that its use would not infringe privately owned rights. Reference herein to any specific commercial product, process, or service by trade name, trademark, manufacturer, or otherwise, does not necessarily constitute or imply its endorsement, recommendation, or favoring by the United States Government or the University of California. The views and opinions of authors expressed herein do not necessarily state or reflect those of the United States Government or the University of California, and shall not be used for advertising or product endorsement purposes.

This is a preprint of a paper intended for publication in a journal or proceedings. Since changes may be made before publication, this preprint is made available with the understanding that it will not be cited or reproduced without the permission of the author.

This work was performed under the auspices of the U.S. Department of Energy by the University of California, Lawrence Livermore National Laboratory under contract number W-7405-ENG-48.

This report has been reproduced directly from the best available copy.

Available electronically at http://www.doc.gov/bridge

Available for a processing fee to U.S. Department of Energy

And its contractors in paper from

U.S. Department of Energy

Office of Scientific and Technical Information

P.O. Box 62

Oak Ridge, TN 37831-0062

Telephone: (865) 576-8401

Facsimile: (865) 576-5728

E-mail: reports@adonis.osti.gov

Available for the sale to the public from

U.S. Department of Commerce

National Technical Information Service

5285 Port Royal Road

Springfield, VA 22161

Telephone: (800) 553-6847

Facsimile: (703) 605-6900

E-mail: orders@ntis.fedworld.gov

Online ordering: http:/ / www.ntis.gov/ordering.htm

OR

Lawrence Livermore National Laboratory

Technical Information Department's Digital Library

http://www.llnl.gov/tid/Library.html 


\title{
Next-Generation Laser for Inertial Confinement Fusion
}

\author{
C. Marshall, C. Bibeau, A. Bayramian, R. Beach, C. Ebbers, M. Emanuel B. Freitas, \\ S. Fulkerson, E. Honea, B. Krupke, J. Lawson, C. Orth, S. Payne, C. Petty, \\ H. Powell, K. Schaffers, J. Skidmore, L. Smith, and S. Sutton, S. Telford \\ Lawrence Livermore National Laboratory \\ P.O. Box 808, Livermore, CA 94551
}

\section{ABSTRACT}

We are developing and building the "Mercury" laser system as the first in a series of a new generation of diode-pumped solid-state lasers (DPSSL) for advanced high energy density (HED) physics experiments at LLNL (see Figure 1 below). Mercury will be the first integrated demonstration of a scalable laser architecture compatible with advanced Inertial Confinement Fusion (ICF) goals. Primary performance goals include $10 \%$ efficiencies at 10 $\mathrm{Hz}$ and $\mathrm{a}<10 \mathrm{~ns}$ pulse with $1 \omega$ energies of $100 \mathrm{~J}$ and with $2 \omega / 3 \omega$ frequency conversion. Achieving this performance will provide a near term capability for HED experiments and prove the potential of DPSSLs for inertial fusion energy (IFE).

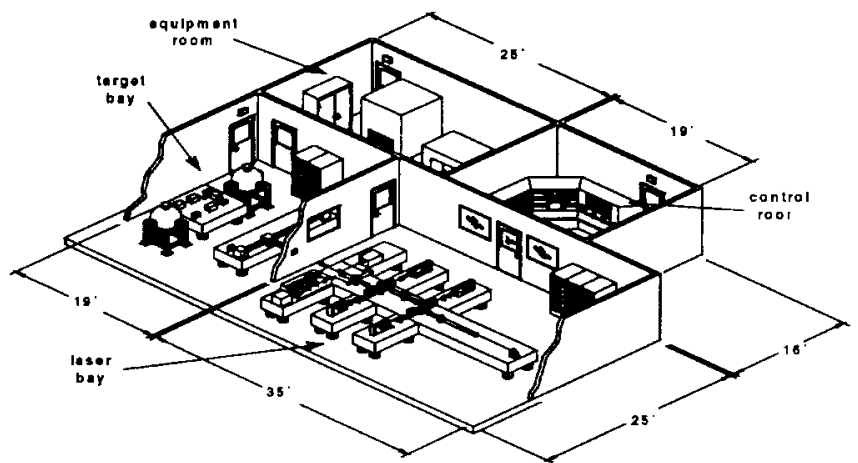

Fig. 1. Conceptual diagram of Mercury laser system.

\section{BACKGROUND}

Over the past 20 years LLNL has pioneered the development and use of high energy lasers for target physics experiments in support of high energy density physics and inertial confinement fusion. The technology upon which this effort has been based is the flashlamp-pumped Nd:glass laser. More than 30 years have elapsed since the first flashlamp-pumped $\mathrm{Nd}$ :glass laser was demonstrated. and this technology approach will soon culminate with the construction of the National Ignition Facility (NIF). Flashlamppumped $\mathrm{Nd}$ :glass lasers have offered crucial advantages (e.g. flexibility in pulse format, wavelength, and spectral width), allowing the progress in ICF physics that has been achieved to date. The slow shot rate of once every few hours, however, limits the number and type of experiments and applications that can be pursued. This limitation need no longer be imposed by the laser technology as first recognized in the early 1980s by Krupke and Emmett. ${ }^{1-2}$ The continuing effort outlined herein will culminate with the development of a new class of high repetition-rate fusion lasers and will produce the first rep-rated solid-state fusion and high-energydensity experimental facility.

The diode-pumped solid-state laser (DPSSL) ICFdriver concept has the important advantage of direct connectivity to NIF and past Nd:glass solid-state lasers such as Nova and Beamlet. The common technical issues with all solid-state lasers such as nonlinear propagation, beam-smoothing, and energy storage/extraction, are numerous; on the other hand, in order to achieve the high rep-rate and efficiency envisioned for this new generation of lasers $(10 \mathrm{~Hz}$ repetition rate and $10 \%$ system efficiency, respectively) it is necessary to replace the flashlamps with semiconductor laser diodes. These systems will be capable of repetition rates up to $10 \mathrm{~Hz}$, which are more than four orders of magnitude higher than those of typical fusion lasers today. Mercury goals outlined in Table I include 100 Joules/pulse that will provide "shots-on-demand" for users. This higher rep-rate laser system could be utilized by constructing multiple specialized-use target chambers and multiplexing the rep-rated laser between them. It will also motivate the development of rep-rated target and diagnostic capability for detailed experimental studies that could map out a broader parameter space. A high rep-rate laser driver will also ultimately be needed if ICF is to provide a means of generating electrical energy. ${ }^{2.3}$ The data in Fig. 2 below depict the progress in the energy of ICF lasers built at LLNL, and how the effort in 


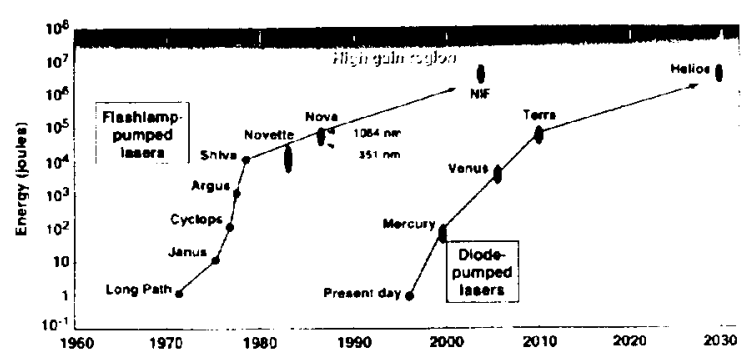

Fig. 2: Plot of the energy from flashlamp-pumped $\mathrm{Nd}$ :glass fusion lasers as a function of time, and the potential time-line for diode-pumped laser development.

diode-pumped solid state lasers is only in its infancy at this time with the Mercury laser as the next major milestone. The proposed Mercury facility will move this technology forward by two orders of magnitude in energy and will take us on the first significant step into this new generation of rep-rated high energy density and inertial confinement fusion lasers.

\section{TECHNOLOGY DEVELOPMENT PROGRESS}

A significant part of our effort has been directed at component research and development for critical areas within the Mercury design such a diode fabrication and costs, crystal growth, advanced cooling concepts, and an integrated system design. We describe the progress of these efforts in more detail below

\section{Laser Architecture and Modeling}

We have assembled a preliminary design for the laser system as shown in Fig. 3. The laser design is predicated upon using a Yb-doped crystal, ${ }^{4-8}$ Ybdoped strontium fluorapatite. Yb:S-FAP offers better diode pump laser costs, due to its long storage time, than the traditional Nd-doped glass gain medium. The laser system utilizes three subsystems for pulse amplification: a fiber oscillator, regenerative amplifier, and two power amplifiers. The final amplification stages are accomplished through four passes of the beam through two gas-cooled amplifier head assemblies. The reverser optics allow the beam to be injected and 4-passed through the amplifiers while preserving the image relaying without the need for an optical switch. A deformable mirror either placed at the end of the amplifier path (as shown) or within the reverser optics path will be used to correct for wavefront distortions incurred during amplification.

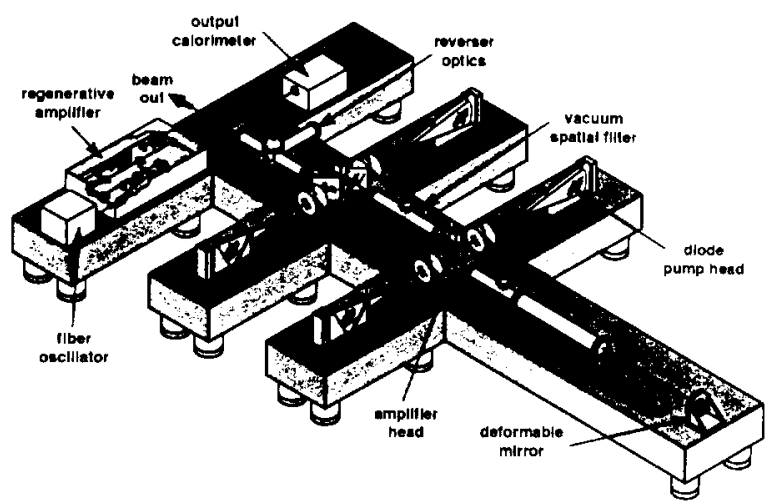

Fig. 3. Mercury laser system layout.

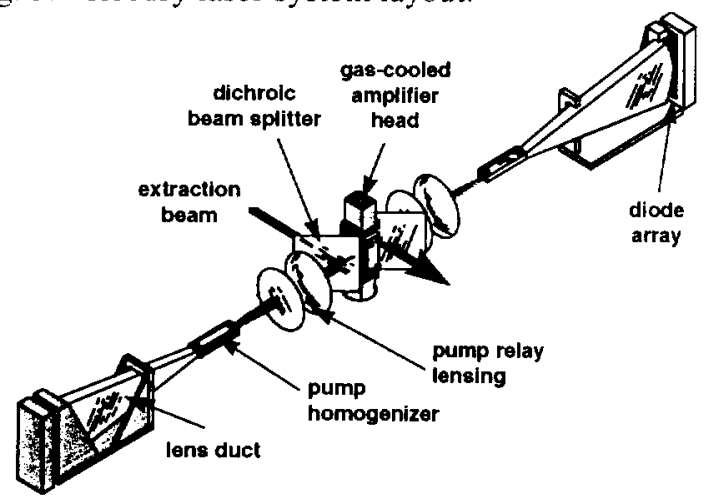

Fig. 4. Diode pumped amplifier head configuration.

A more detailed picture of the power amplifier pumping geometry is shown in Fig. 4. The amplifier head will be optically pumped from both sides. The dual pumping design allows for more uniform pumping and thermal loading on the crystals. The light from the diode array light is first condensed with a lens duct followed by an optical element which homogenizes the spatial profile of the pump beam. The light emerging from the output of the homogenizer is imaged onto the gain media with a pair of lenses. The angled dichroic beam splitters allow the pump beam to pass through the optic and into the amplifier head while allowing the extraction beam to be reflected.

We have developed a baseline performance code to model energy flow in the Mercury laser system. This modeling code performs optimization and tradeoff studies to define the system design. To keep the analysis manageable, several approximations have been made in describing the pump excitation and laser energy extraction physics as detailed below.

First, we model the laser diode pump array performance including the effects of transient heating during the laser diode pump pulse. Transient diode heating is accounted for by dynamically 
tracking the roll-ott in diode array output poster. and the red shift in the diode emission spectrum. with increasing temperature during the pulse. In addition to the contribution of diode chirp to the pump spectrum. the entire array is characterized by a Gaussian distrihution of wavelengths representing the spread in the center wavelengths of the approximately 6400 individual diode bars that will comprise the entire pump array. The peak power capability of the array is $640 \mathrm{~kW}$ with a $1 / \mathrm{e}$ spectral half-width of $+8 \mathrm{~nm}$ that describes the pump array radiation. A thermal diffusion model that is anchored to experimental data is used to describe the transient temperature rise experienced by the diode array during a pump pulse.

The code next treats the transport of the laser diode array pump radiation into the Yb:S-FAP slabs. A ray propagation treatment is used to track the pump radiation through a lens duct and homogenizer. One of the critical parameters that characterizes the laser diode array performance for the pump delivery architecture that is being pursued here is the divergence of the radiation in both the slow and fast axis directions. To control the fast axis divergence. each diode bar has its output radiation conditioned by a shaped cylindrical microlens."

The microlens conditioned fast axis divergence of the diode array is characterized by a FWHM of 10 $\mathrm{mRad}$ in the diode fast axis and $150 \mathrm{mRad}$ in the perpendicular slow axis which is consistent with the data obtained for a prototype diode array described below. After the pump light is conditioned by the shaped cylindrical micro-lenses it is delivered to a lens duct having the same dimensions ats the slab aperture which is to be pumped. Because efficiency is the driving consideration in the design of the laser system. the lens duct is designed to have maximum transfer efficiems without regard for the uniformity of the radiation at its and.

It is critical that the slabs be uniformly pumped of enahle the extration of a high quality laser heam. which requires a tuniform intensity pump beam Developing and embancing this capahility hats gemeral application in IPPSsl systems, To accomplish this. the pump radiation an the lens duct output end is hembented he heme tramsported a short distance

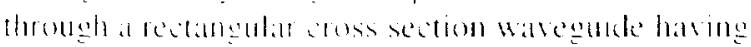

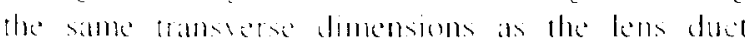

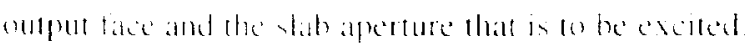

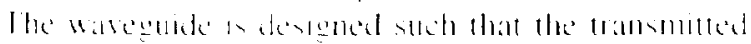

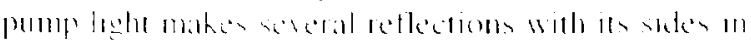

the process of tattling down it's lenght Thene reflections effectively homogenize the pump light intensity across the wateguide aperture by the lime the light reaches its output end the pump light emerging from the output end of the homogenter is then imaged onto the first slat in the stack of seven slabs that are housed in the gas-cooled head.

The code we developed then forward propalgates the pump radiation through the 7 slabs comprising the gain module to calculate 2-dimensional pump deposition profiles at each slab. as well as slat edgecladding optical loading values. This kast porton of the code approximates the physies associated with the pump excilation process. The ray trace portion of the modeling code is normalized by using a 1 dimensional pump pulse propagation model. This propagation code dynamically calculates the gain loading of the individual laser slabs using a treatment that includes the effects of $\mathrm{Yb}^{2+}$ ground state depletion. spectrally selective pump wave depletion. $\mathrm{Yb}^{3+}$ fluorescence decay. and amplified spontaneous emission which is handled using a simplified treatment.

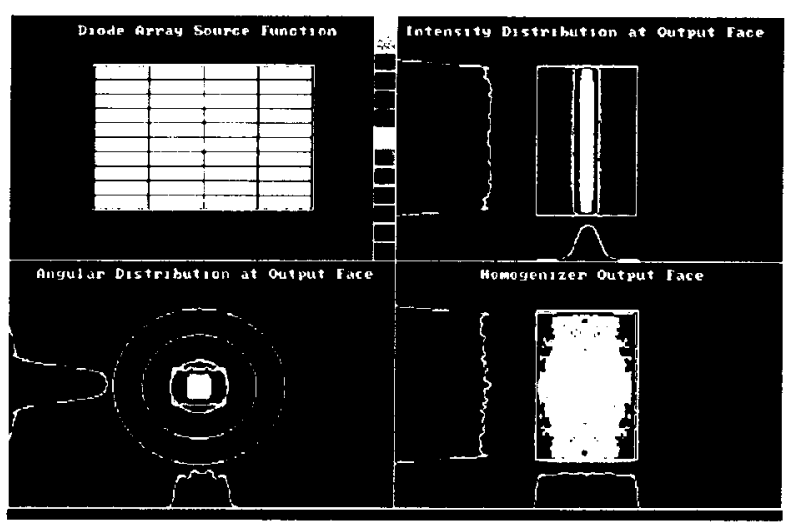

Fig. 5. Pump intensity at various locations in the pump chan. (lockwise from upper left: (1) The diode pump array. (2) The intensity at the outpun of the lens duce. (3) The angular distribution of the light that exits the lens duct with circles atre at 15.30 and t5 from the optic axis.

Ihe oupue of this I-dimensional conte is used for normalize the z-dintensional eneres deposition

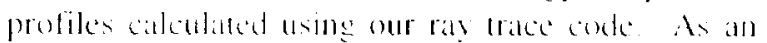

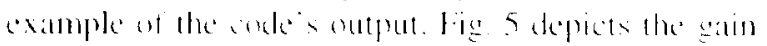

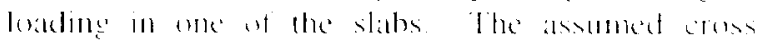

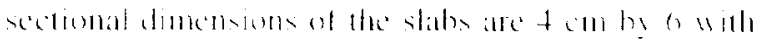

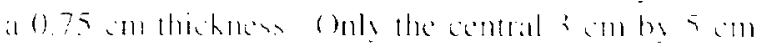

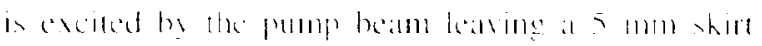

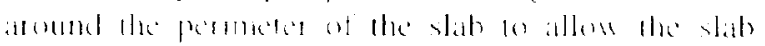

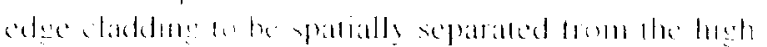


intensity pump radiation. Another feature accounted for in our modeling is the geometrical overlap of the left and right counter-propagating pump beams with the extracted area of the slabs in each stack. The left-going pump is imaged onto the extracted region in the right most slab and the right going pump is imaged onto the extracted region in the left most slab. This results in the pump beams diverging out of the extracted regions as they propagate away from the outermost slab they were imaged on. The 3-D ray trace code allows us to quantify the fractional pump deposition within the slab-extracted area on a slab by slab basis. The pump spatial profile leads to uniform heating of the laser slabs as shown in Fig. 6 , while the geometric overlap integral between the slab extraction mode and the pump beam is shown in Fig. 7. It can be seen from Fig. 7 that the pump and extraction modes are well overlapped at greater than $90 \%$ efficiency for all crystals.

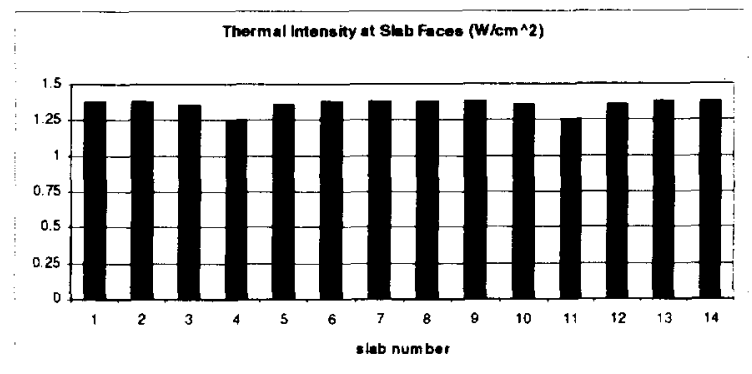

Fig. 6. 2-D pump deposition profiles of the $\mathrm{Yb}: \mathrm{S}$ FAP lead to uniform thermal distributions.

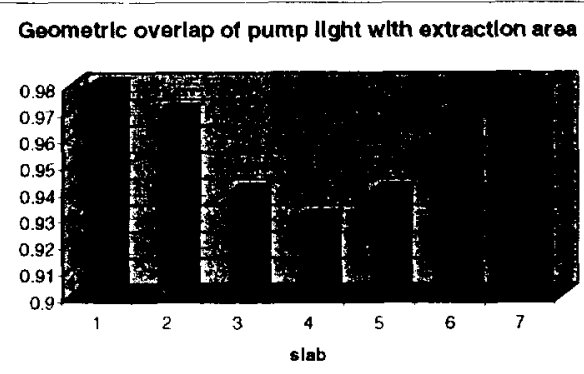

Fig. 7. Fractional pump deposition within the extracted area of each slab, or the overlap integral, as calculated by our 3-D pump propagation code.

One of the issues that we have addressed with our modeling capability is the specification of the slabto-slab dopings to both optimize laser performance and keep the thermal load from slab to slab balanced. The balancing of the thermal load from slab to slab is an important consideration for the optimum performance of the gas cooling being employed here which is accomplished by using three different doping values of $1.4 \times 10^{19} / \mathrm{cm}^{3}, 1.7 \times 10^{19} / \mathrm{cm}^{3}$, and $2 \times 10^{19}$. See Orth et. al. ${ }^{3}$ for a discussion of the gas cooled laser slab technique.

Energy extraction modeling uses a standard FrantzNodvik analysis that has been modified to account for the quasi-three level nature of the $\mathrm{Yb}^{3+}$ ion to calculate the gain-log and saturation fluence after each pass through the system.

Figure 8 shows one impact of the narrow absorption feature on the pump excitation radiation. The integrated pump power spectrum after the slabs exhibits a spectral hole burned into it by the absorption of the $\mathrm{Yb}^{3+}: \mathrm{S}-\mathrm{FAP}$. Because one of the driving design considerations of the laser system is the optimization of its efficiency, the developed code is critical for specifying desired diode operating characteristics as well as performing system sensitivity studies of these diode characteristics.

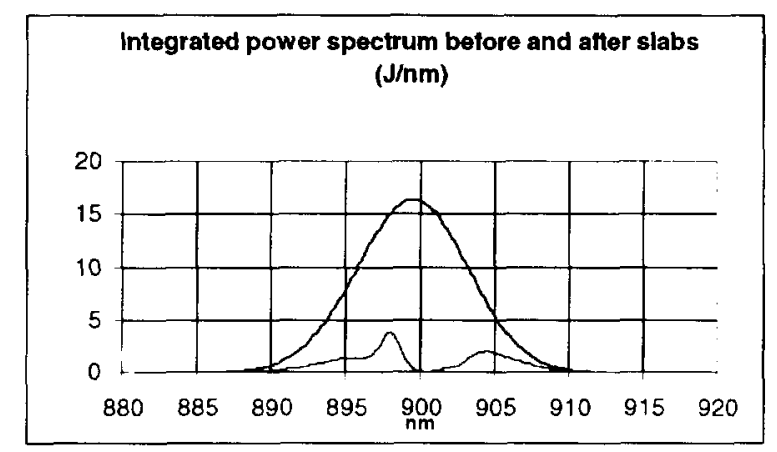

Fig. 8. Integrated pump power spectrum before and after slabs.

Figure 9 shows the extracting pulse fluence and the net gain-log of the 14 slabs as a function of the pass number during the four-pass extraction. The final slab to be traversed by the extracting pulse is projected to see a reasonable fluence of $9 \mathrm{~J} / \mathrm{cm}^{2}$. In addition the code also performs a path integral of the local extraction pulse irradiance, assuming temporally square extracting pulses, which is in turn used to calculate a B-integral for the system. 


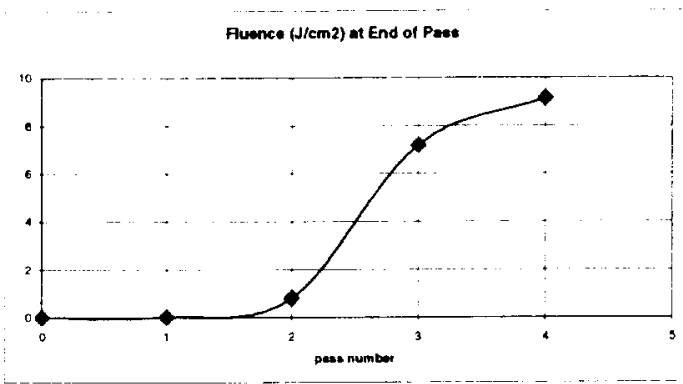

Fig. 9. (a) Extracting fluence of the 14 slabs that comprise the amplifier system as a function of the pass number during the four-pass extraction.

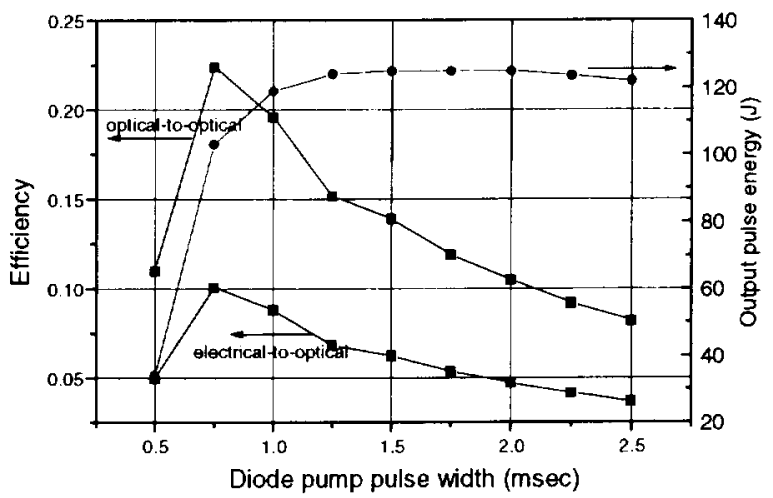

Fig. 10. Mercury laser system performance versus diode pump pulse duration. An assumed diode wall plug efficiency of $45 \%$ (electrical-to-optical) is used in generating the electrical-to-1047 $\mathrm{nm}$ optical efficiency curve.

One example of a sensitivity study is shown in Fig. 10 where both efficiency and output pulse energy are plotted against the pump pulse duration. In terms of pulse energy output and overall efficiency, the goal of the Mercury laser system is $100 \mathrm{~J}$ and a wall-plug efficiency of $10 \%$. Using an assumed diode efficiency (electrical-to-optical) of $45 \%$ these goals can be met with a pump pulse duration of $750 \mu \mathrm{sec}$. Initial extraction propagation modeling for the baseline configuration has been completed using the PROP92 code in 3D $(x, z, t)$ developed for NIF. Based on estimated $\mathrm{Yb}$ :S-FAP gain profiles obtained from the 2D $(z, t)$ modeling described above, these runs veritied the Mercury goals of a focal spot smaller than 5 times diffraction limited with an deformable mirror containing at least $100 \mathrm{~J}$. The 3D calculations also set limits on the Yb:S-FAP optical specifications such as bulk loss of $1 \%$ per $\mathrm{cm}$ which has been experimentally demonstrated. In addition. the calculation sets wavefront distortion limits on the laser crystals as a function of spatial frequency. Figure 11 presents the allowable wavefront distortion in terms of a power spectral density (PSD) versus spatial frequency. A straight line at twice the level of this distortion is shown in Fig. 11 along with wavefront-distortion measurements of a Yb:S-FAP crystal. Figure 11 demonstrates that we can grow crystals with wavefront distortions within a factor of about two of what is needed for Mercury. Crystal growth progress is described below. Calculations planned for the rest of 1998 include 4D PROP92 runs in $(x, y, z, t)$ to better understand transverse nonlinear effects.

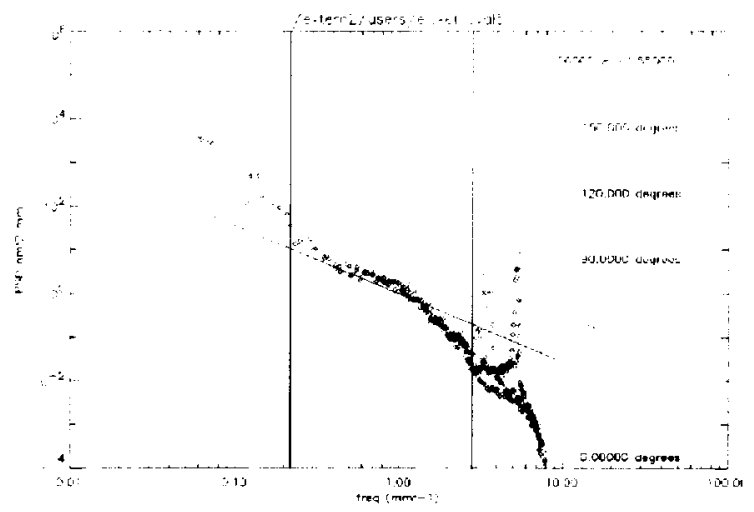

Figure 11. Wavefront distortion specified as a power spectral density (PSD) versus spatial frequency. Data point are from measurements on $\mathrm{Yb}: \mathrm{S}$-FAP crystals. Relevant region on the plot lies between the two vertical lines.

\section{Diode Arrays}

The laser diode array module is shown in Fig. 12. The heatsink is formed from a monolithic substrate that is thermally conductive but electrically insulative. Metalization provides electrical continuity from one side of the bar and a spring (or solder) is used to connect the backside of the bar to the adjacent metalization layer. Since the active layer of the diode bar rests firmly against one side of the slot, accurate alignment of the laser diode is ensured which enables precision microlens alignment to the arrays of reduced complexity and with accurate alignment registration (i.e., to increase the effective brightness).

Fabricating diode heatsink structures in $\mathrm{BeO}$ presents challenges precision engineering technology. We have selected $\mathrm{BeO}$ as the heatsink material by considering the trade off in thermal performance with ease of fabrication. In addition, we have fabricated 40-bar heatsinks in which all of the feature tolerances are kept to within $\pm 5 \mu \mathrm{m}$. The arrays are designed to accept $1 \mathrm{~mm}$ diode cavity lengths to increase the thermal footprint of the diodes, thereby 
mitigating the power droop associated with thermal transients. A 40-bar array was fabricated from 940 $\mathrm{nm}$ laser bars that were grown and fabricated at LLNL. As shown in Fig. 13a, the array was operated up to $4.1 \mathrm{~kW}$ of peak power $\left(1.03 \mathrm{~kW} / \mathrm{cm}^{2}\right)$ with an electrical to optical efficiency of $50 \%$. This exceeded our goal of $1 \mathrm{~kW} / \mathrm{cm}^{2}$. As shown in the figure, the power level at the beginning and end of the pulse are nearly the same, indicating little power loss from thermal transients during the pulse. The $900 \mathrm{~nm}$ diode bars that will be used for Mercury have been life tested under accelerated conditions $(100 \mathrm{~W}, 100 \mathrm{~Hz}, 750 \mu \mathrm{s})$ and have exceeded $10^{8}$ shots with $<30 \%$ current rise (produced by CoherentTutcore, Finland)

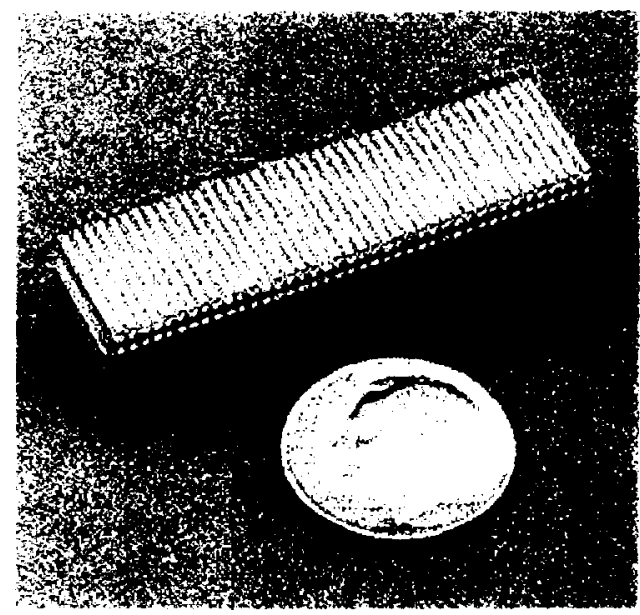

Figure 12. (a) Diagram of prototype BASIS 40-bar laser diode array built in 1998.

In Fig. 13b, the angular divergence (fast axis) is shown for the same array after microlensing. Precision lens frames were fabricated from Si via wet etching and the microlenses were fiber-pulled from an aspherically shaped pre-form. The divergence was measured to be approximately $40 \mathrm{mRad}$ with $85 \%$ collection of the energy output which meets the performance requirements for Mercury.

Conceptual design of the control system and diagnostics for the laser diode pulse power system is complete. The design focuses on ease of operation and protection of the laser diodes. Computer based diagnostics will monitor the current and voltage for each diode sub-array in real time. The data will be presented as a "waterfall" array allowing quick operator verification of normal operation.

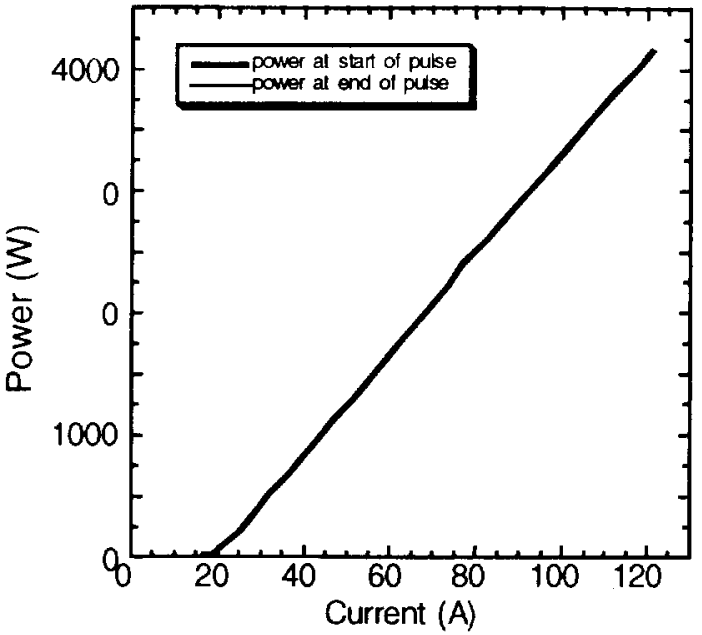

Figure 13. (a) Light output versus current characteristics for a 40-bar array at a peak power level of $4.1 \mathrm{~kW} / \mathrm{cm}^{2}$.

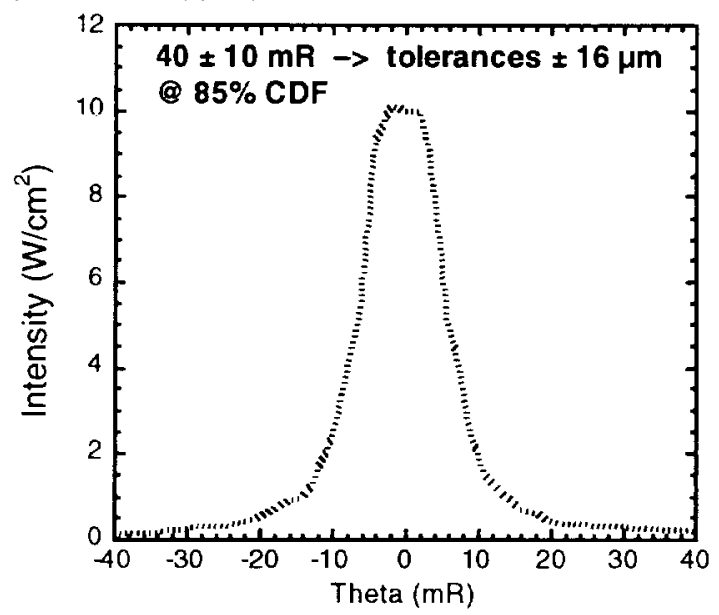

Figure 14. Divergence of array output emission perpendicular to the active layer following a single active alignment step.

\section{Crystal Growth}

The goals of the crystal growth efforts for the Mercury project are to assess the growth potential of $\mathrm{Yb}: \mathrm{S}-\mathrm{FAP}\left[\mathrm{Yb}^{3+}: \mathrm{Sr}_{5}\left(\mathrm{PO}_{4}\right)_{3} \mathrm{~F}\right]$ crystals, develop a resource for the growth of full size crystals, and investigate the capability and integrity of the fusion bonding process to attach the cladding layers for large scale crystals $(4 \times 6 \times 0.75 \mathrm{~cm})$.

Significant progress has been made in understanding the growth characteristics and defect chemistry of $\mathrm{Yb}: S-F A P\left[\mathrm{Yb}^{3+}: \mathrm{Sr}_{5}\left(\mathrm{PO}_{4}\right)_{3} \mathrm{~F}\right]$ crystals which has helped provide high optical quality material for the Mercury laser. Yb:S-FAP crystals are typically grown by the Czochralski method. This laser 
requires crystalline slabs of dimension $4 \times 6 \times 0.75$ $\mathrm{cm}^{3}$ for the active gain region. Growth of sufficient size crystals to provide these slabs is challenging due to a number of defect structures, including cloudiness in as-grown boules, core defects, slip dislocations, and cracking in larger diameter boules $>$ $4.0 \mathrm{~cm}$. In an effort to understand each of these defects and determine a feasible growth technique for producing high optical quality crystals during 1998, a collaborative effort was put forth between LLNL, Crystal Photonics Inc., and Scientific Materials Inc., to study the growth of $\mathrm{Yb}: \mathrm{S}$-FAP. This effort is described by Schaffers et. al. in another paper of this same volume of Trends in Optics and Photonics.

\section{Thermal Management}

The Mercury laser head and gas cooling architecture are being designed in a modular format, for which the laser slabs are mounted in a vane element, as shown in Fig. 15. The vane elements are then stacked to form the laser head assembly, a cross-section of which is depicted in Fig. 16. Between each of the flow vanes is a cooling channel to remove the waste heat from the laser slabs ${ }^{13.14}$. Upstream of the constant area channel section are nozzle elements where the helium cooling flow is accelerated to Mach 0.1 . Downstream of the channel section are diffuser elements (both in the vanes and in the containment structure) where the helium flow is decelerated.

Significant progress has been made on the design of the laser head, specification of the gas cooling system, and prediction of the thermally induced optical distortions in the laser medium. The 7-slab laser head fabrication is now in progress. Detailed fluid dynamic simulations of flow within the channel and diffuser sections of the system were performed to produce a design with minimum potential for flow instabilities. Detailed finite element simulations of stresses in the optical windows were performed to ensure compliance with design safety criteria.

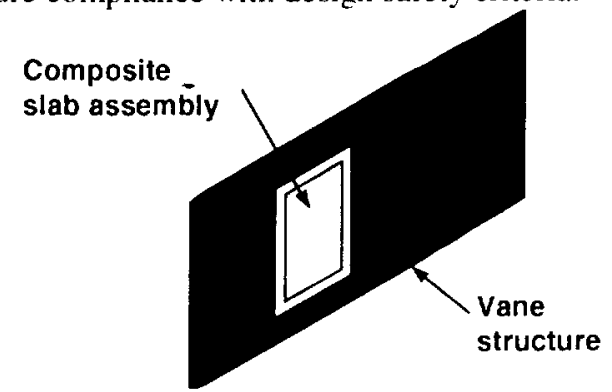

Fig. 15. Composite crystal assembly embedded into cooling vane structure

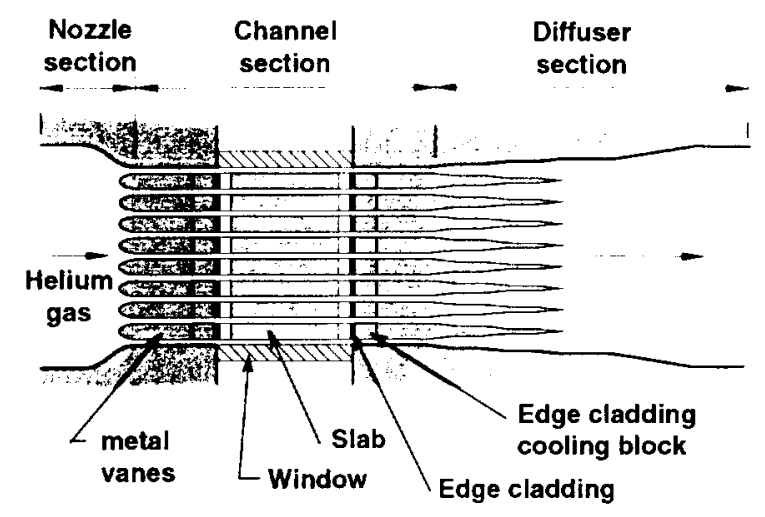

Fig. 16. A schematic of the cross-section of a Mercury laser head showing the stacked vane structure with yellow cooling channels between each vane.

Detailed thermo-mechanical calculations of the laser slabs have been performed. The simulations included details of the thermal source distribution in the laser slabs, details of cooling flow boundary conditions, and mechanical and thermal details of the slab mounting configuration. These calculations indicate that thermal distortions are predominantly driven by pump roll-off at the edges of the aperture and conduction of heat from the central hot portions of the aperture to the cooler periphery. The optical phase distortion is predicted to be 0.17 waves/slab/pass, which translates to 9.5 waves of distortion for the 14-slab, 4-pass optical system. This amount of wavefront distortion is similar to that predicted for other advanced ICF lasers such as NIF ( $<15$ waves). In all solid-state ICF laser systems including Mercury, the thermal distortions are of low-spatial frequency and as a consequence are amenable to correction with adaptive optics or tailored phase plates.

\section{Summary}

There are significant technical challenges incorporated into the Mercury development plan that will advance key elements of laser technology by orders of magnitude. For example, we will advance the scale of the diode array peak output powers to $\sim 1$ $\mathrm{MW}$ and simultaneously maintain high brightness. This effort will also develop the largest Yb:S-FAP optical elements by a factor of six in volume. The gas-cooled-slab architecture will enable high peak power (up to TW) lasers to be extended to large output powers of up to $>1 \mathrm{~kW}$ average power. In addition. this will be the highest energy/pulse diode- 
pumped laser ever built by an order of magnitude. Achievement of these and other significant advances will make this project extremely challenging within the current scope of schedule and budget.

The Mercury project is developing the nextgeneration high-energy-density and fusion laser. Flashlamp-pumped Nd:glass systems have served as a central technology by which the physics of ICF and high energy density plasmas have been explored over the last two decades. Laser technology has progressed, however, such that it is now possible to envision systems that are not repetition-rate limited.

\section{References:}

1. W. F. Krupke, Fusion Technol. 15, 377 (1989).

2. J. L. Emmett and W. F. Krupke., Sov. J. Quantum Electron. 13,1 (1983).

3. "A diode pumped solid state laser driver for inertial fusion energy", C. D. Orth, S. A. Payne, and W. F. Krupke, Nuclear Fusion 36(1) 75 (1996).

4. "Ytterbium-doped apatite-structure crystals: a new class of laser materials", S. A. Payne, L. D. DeLoach, L. K. Smith, W. L. Kway, J. B. Tassano, B. H. T. Chai, and G. Loutts, J. Appl. Phys. 76(1) 497 (1994).

5. "Laser, optical and thermomechanical properties of Yb-doped fluorapatite", S. A. Payne, L. K. Smith, L. D. DeLoach, W. L. Kway, J. B. Tassano, and W. F. Krupke, IEEE J. Quantum Electronics 30(1) 170 (1994).

6. "Laser and spectroscopic properties of $\mathrm{Sr}_{5}\left(\mathrm{PO}_{4}\right)_{3} \mathrm{~F}: \mathrm{Yb}^{\prime}$, L. D. DeLoach, S. A. Payne, L. K. Smith, W. L. Kway, and W. F. Krupke, J. Opt. Soc. Am B 11(2), 269 (1994).

7. "Diode-pumped ytterbium-doped $\mathrm{Sr}_{5}\left(\mathrm{PO}_{4}\right)_{3} \mathrm{~F}$ laser performance", C. D. Marshall, L. K. Smith, R. J. Beach, M. A. Emanuel, K. I. Schaffers, J. Skidmore, S. A. Payne, and B. H. T. Chai, IEEE J. of Quantum Electronics 32(4) 650 (1996).

8. " $1.047 \mathrm{~mm} \mathrm{Yb:Sr5(PO4)3F}$ energy storage optical amplifier", C. D. Marshall, S. A. Payne, L. K. Smith, H. T. Powell, W. F. Krupke, and B. H. T. Chai, IEE J. of Selected Topics in Quantum Electronics 1(1), 67 (1995)

9. J. J. Snyder, "Cylindrical microlenses", Proc. SPIE, 1992, I4 (199:)

10. R. J. Beach, "Theory and optimization of lens ducts", Appl. Opt., 35. 2005 (1996).

11. See for example, Measurement of the inhomogeneity of a window, Chaiyu, $\mathrm{Ai}$ and James E. Wyant, Optical Engineering. 30(9), 1399 (1991).
12. "Power spectral density specifications for highpower laser systems", J.K. Lawson, D.M. Aikens, R.E. English, Jr., C.R. Wolfe, SPIE Proceeding 2775, "Specification, Production and Testing of Optical Components and Systems", pp. 345 (1996).

13. S. B. Sutton and G. F. Albrecht, J. Appl. Phys. 69, 1183 (1991).

14. G. F. Albrecht, et al., Appl. Opt. 29, 3079 (1990).

15. International Atomic Energy Agency, "Physics Activities", 97-02190 (1997). 